\title{
Strategies to Enhance Student Learning in a Capstone MIS Course
}

\author{
Anil Kumar \\ Central Michigan University, Mt. Pleasant, MI, USA
}

anil.kumar@cmich.edu

\begin{abstract}
The information systems marketplace is changing rapidly requiring students to be well versed in skills that go beyond traditional IT skills. To achieve this, management information systems (MIS) instructors in MIS programs across the country need to design courses that reflect these changes. Failure to incorporate these changes in the MIS program will lead to graduating MIS students who are not competitive in the marketplace. While curriculum changes are often times a time consuming process, the capstone course in an MIS program can be used effectively to reflect these changes. This paper highlights different strategies that can be used in a capstone MIS course to help students synthesize, analyze, and apply knowledge acquired over different courses in the program.
\end{abstract}

Keywords: Capstone MIS course, student learning, systems approach, assessment, integrated learning

\section{Introduction}

The capstone course in any program of study provides a student the opportunity to synthesize, analyze, and apply knowledge acquired over different courses in the program. This course enhances the overall education experience of students by helping them understand the big picture, i.e. how knowledge acquired from all the courses in their curriculum converges together. For example a management information system (MIS) student learns several concepts and acquires multiple technology skills in different courses that are a part of the MIS program and then learns how to apply all these concepts and use the skills to design and develop an information system. Knowledge integration and application in a capstone MIS course can be a challenging task. An instructor designing the capstone course needs to ensure that critical components from all the courses in a program are integrated.

Designing a capstone MIS course is challenging due to factors such as the need to integrate business concepts and technology concepts \& skills, the diversity of IT skills and the rapid rate of change in the IT industry. Scholars (Lopes \& Morais, 2002; Neville \& Adam, 2003) have high-

Material published as part of this publication, either on-line or in print, is copyrighted by the Informing Science Institute. Permission to make digital or paper copy of part or all of these works for personal or classroom use is granted without fee provided that the copies are not made or distributed for profit or commercial advantage AND that copies 1) bear this notice in full and 2) give the full citation on the first page. It is permissible to abstract these works so long as credit is given. To copy in all other cases or to republish or to post on a server or to redistribute to lists requires specific permission and payment of a fee. Contact Publisher@InformingScience.org to request redistribution permission. lighted the need to provide an integrated (business and information technology) experience to information technology students in a capstone course. Neville and Adam (2003) state that this enables students to develop skills that they can use immediately to "contribute to the organizations that hire them.” Lopes and Morais (2002) point out that IS courses need to be "frequently updated to remain effective" due to the nature of the 
evolution and advancement in the IT industry. Noll and Wilkins (2002) highlight the diversity of skills needed by the IS industry and the fact that a generic IS program cannot provide these skills to students. They recommend "distinct concentrations" such as "programming, analyst and user support” that provide diverse skills to students.

MIS capstone course studies highlight using the project experience as a pedagogical approach to teaching the capstone course. Studies like Myers (2003) and Tuttle (2001) provide useful insights from using the project-based approach to increase student learning in a capstone IS course. Tuttle (2001) does go beyond the project experience and describes the course structure, methodology and student feedback. These studies fail to take a comprehensive view of the MIS capstone experience and this is the gap the present study is trying to address. Students need to learn about the integration and convergence of not just the MIS curriculum but the complete academic experience. They need to learn how to successfully synthesize, analyze, and apply knowledge acquired in an academic program in the capstone course. This will help them gain an advantage in the highly competitive MIS marketplace, leading to successful careers in the MIS discipline. MIS programs across the nation can highlight these success stories leading to increased student enrollment in the MIS programs. The challenge for educators is to design a capstone MIS course that provides students the opportunity to learn and succeed in their chosen field. This paper shares strategies that have helped students synthesize, analyze, and apply knowledge in a capstone MIS course. The author is a MIS faculty and has taught the MIS capstone course at both the undergraduate and graduate level for several years in a Midwestern university.

\section{Strategies for Teaching a Capstone MIS Course}

A capstone course in any discipline requires that students are provided the opportunity to synthesize and integrate their knowledge acquired over several years. This creates unique challenges for the designer of the course as one has to ensure that students walk away from this course with a good understanding of how knowledge acquired from all their courses in their curriculum fits together and how they can apply this knowledge to design and develop an information system.

\section{Using the Systems Approach}

It is critical to start the capstone course by a discussion of the systems approach to designing and developing information systems. The systems approach encourages students to look at different courses as elements that need to interact rather than be studied as individual courses. As Friedman (2005) points out "the world is moving from a place where value was created in vertical silos of command and control to a world where value is increasingly going to be created horizontally by how you connect and collaborate - how you synthesize this with that... It's great to have people who can forge dots, it's even better to have people who can connect them.” The ability to understand how different courses are building blocks (dots) in the process of acquiring integrated (connecting) MIS knowledge can help students understand and relate the diverse concepts and skills used to design and develop information systems.

Using the systems approach the course content was divided into several modules. Concepts discussed and learned in a course module were reinforced by a project milestone helping students apply the concepts. A project management approach was used for managing these projects where each student in the group was made responsible for managing the project for a milestone. This exposed students to the challenges of managing an Information System project. The capstone project was designed keeping in view the systems theory approach to designing and developing an information system. 


\section{Using a Student-Centered Rather than a Teacher-Centered Ap- proach to Enhance Student Learning in the Classroom}

A student-centered teaching approach was used to actively engage students in the learning process. Student learning is the focal point of my teaching and in pursuing this effort the goal has been to answer how will students learn rather that how do I teach them? A conscious effort was made to increase student involvement in the classroom to promote student learning. Instead of using a teacher-centered approach where students receive information passively and tend to lose interest, a student-centered approach was used. To achieve active participation in the classroom, class lectures were made available to students on Blackboard a week before class. The students were expected to read the assigned chapters and presentations and come prepared to class. Classroom time was used for discussions and problem solving exercises to learn the theory and concepts of MIS. This strategy facilitated the transition to student-centered learning and also ensured active participation from students.

This approach enhanced the overall learning experience for the students as indicated by their comments provided as part of the end of the semester evaluations:

"Presents the material in a way that helps us learn, by asking questions and getting our thoughts instead of just lecturing."

"He structured the class around the students. It was the only class I enjoyed coming to."

"Good open discussions. Good use of examples. It was good that he was open to student suggestions."

"I liked how the teacher got us involved through group discussions and presentations. The class was lively and as a result I was very motivated in attending every single class. The teacher is very approachable and makes students comfortable.”

"Lots of questions and interactivity during lecture."

To use the student-centered approach a significant effort was made every semester to know individuals in the class. This was achieved by using several ice-breaking activities in the first class to know more about the students-their names, hobbies, background etc. In the first class I shared experiences with them and encouraged them to do the same. This process is critical and often leads to motivating students. Motivated students tend to be more receptive to learning. When designing the course make sure that the first class meeting is planned for developing the rapport with students. This prepares students to interact actively with the instructor and other students leading to an environment that promotes active learning in the classroom.

\section{Use Multiple Assessment Methods to Ensure that Students with Diverse Learning Styles have an Opportunity to Demonstrate their Learning}

Every semester students were required to complete a questionnaire at the beginning to identify their learning styles, and multiple course assignments \& projects were designed to accommodate diverse student learning styles. The Grasha-Riechmann Student Learning Style Scale (HruskaRiechmann \& Grasha, 1982) that identifies six types of student learners, Independent, Collaborative, Dependent, Participative, Competitive, and Avoidant was used to identify student learning style. This was done with a view to ensure that students with diverse learning styles in my classroom had an opportunity to demonstrate their learning. A critical part of the assessment process was to provide ongoing feedback to students about their performance. This enhanced student learning as they were always aware of the progress they were making and could focus on things that they needed to improve. 
Students' ability to comprehend concepts of management information systems design and development were assessed using a two-phased approach. Initially classroom discussions were used for assessing student understanding of concepts and their ability to demonstrate this understanding orally in a group setting. As a follow up measure to reinforce their understanding individual students were asked to write up a reflective paper for each course module completed in class. This reflective paper required students to answer questions on the different concepts discussed in the module. For example, the module on logical design required them to discuss the significance of modeling (data and process), and students were required to discuss the concepts using examples from their project. In addition, students were asked to create a concept map that allowed them to depict pictorially how concepts in each module were related to each other. The concept map enabled students to see the big picture from an integrated learning perspective. Instant feedback was provided to students in the classroom during discussions. Reflective papers were graded and returned to students with comments before the next class period. All course grades were posted on Blackboard and students were able to track their progress throughout the semester.

The following end of semester student comments indicated that usage of multiple assessment methods promoted student learning.

"The whole project milestone idea was great and it made me have a first-hand development of a system. The reflective paper was also good."

"Gives examples. Sits down w/students \& explains the material. Posts documents on Blackboard. Uses email to communicate with students.”

"By dividing the system work into Milestones and also asking students write reflective papers make it easy on me to really know what is going on step by step.”

\section{Integrate Technology to Promote Student Learning}

Technology usage was a critical component of my teaching. Technology was used as a tool to support and promote active student learning. Blackboard (BB) was used as a course management system to support student learning. All course materials such as course syllabus, course content presentations, assignments, announcements, student grades etc. were made available to students on BB. Further, BB group communications features have been used consistently to promote active student learning. Students have been required to interact with their peers electronically to exchange ideas on different topics being discussed in class. This promoted collaboration within and among groups in the class and prepared students for the real-world where electronic collaboration is highly desired.

Numerous technology tools such as MS-Project, MS-Visio, MS-IIS 6.0 web server, MS Office Suite, MS SQL Server, Oracle, HTML, MS-FrontPage, Active Server Pages, Cold Fusion, Dreamweaver etc. were used in the class to help students develop skills required for designing and developing computer-based information systems. Students used these tools to develop systems that simulate real world organizations. Examples from previous semesters include: day care registration \& information management system, student flea market system, and entertainment \& dining information system for a small community among others. Students were encouraged to use technology tools extensively to enhance their learning and provide an opportunity for them to manage and operate technology for their projects. For example, at the beginning of the semester, all systems development software was provided for free from Microsoft through the University Alliance. It provided the students the opportunity to practice working with the software in their own time outside of class throughout the first half of the semester and finally use it to implement their systems in the second half of the semester. Partnering with the College of Business Administration technology department, students were provided access to virtual MS-Windows servers. To enhance the learning process students were provided the opportunity to build and maintain IIS 
6.0 web servers to host their systems. A unique feature of this process was that these web servers were developed and maintained by students using virtual server management tools. All students in the course were given administrative rights to these virtual servers and responsibility for running, maintaining and security was delegated to the students. This unique feature enabled students to understand how organizations create an IT infrastructure to manage their systems and the associated challenges that MIS professionals face in managing them. Though technologically frustrating at times, the students enjoyed the "power" they had in managing their systems. The MIS design and development projects used for application of concepts in the capstone MIS course need to address the complexity of the process, yet should be simple enough so that students can complete them in a semester's time.

\section{Integrating Student Learning, Assessment \& Feedback and Technology Usage to Enhance Student Learning}

The key to my teaching strategy was the integrated approach that was used to design the capstone course. Student learning, assessment \& feedback and technology usage were integrated for course design to achieve alignment with the mission of the University and the College of Business Administration. The integrated approach was implemented by first listing the three components, i.e., student learning outcomes, assessment procedures \& feedback, and technology usage and then ensuring that these three components were aligned with each other and supported each other. The benefit of using this integrated approach was that the focus of the course was on achieving student learning outcomes.

Student comments indicated that they liked the integrated learning approach that was used in the classroom.

"Lectures are interactive. Extensive use of Blackboard helps too. Instructor also involves students in design of class \& making decisions about assignments, tests, quizzes etc.”

"The format of the class was excellent-discussions were well paced. Papers/case analysis to test knowledge is more "real-world" than testing."

\section{Collaborating with Students on Multiple Research Projects}

I am a strong believer in encouraging my capstone course students at both the undergraduate and graduate level to conduct quality research as part of their academic career. In pursuit of this goal during the past three years I have co-authored peer review journal articles, research monographs, and presented multiple papers at International conferences with my students.

\section{Inviting Recent Graduates to Speak to Capstone Course Students}

In an attempt to help capstone students understand the IS industry environment, recent MIS graduates were invited to speak to the class. This helped calm students' fears about entering the workplace and prepare them for the transition. Speakers that have participated have come from companies such as Deloitte Consulting, Eli Lilly, EDS, and Dow Chemical etc. These speakers were in addition to senior industry professionals that have visited the capstone classes from time to time to talk about job potential in the IS discipline. 


\section{Conclusion}

As discussed in the previous sections, this paper highlights multiple strategies used to actively involve students in the learning process leading to enhanced student learning and engagement in their capstone MIS course. Students, individually and in groups, always participated in both classroom and online discussions. The prompt feedback provided to students on their performance helped them assess their own knowledge on a specific topic before moving to the next topic in class. Technology was integrated as a critical component of the classroom to extend the learning environment beyond the traditional classroom. Since students learn in different ways it was ensured that multiple opportunities were provided to students to demonstrate their learning. I believe that using these innovative approaches has challenged the students to set high expectations for them to excel in the classroom. Student opinions indicate that they liked the challenge and the high expectations set for them in the course and their performance in the form of grades, research publications, and international conference presentations etc. indicates the success of these innovative approaches.

\section{References}

Friedman, T. (2005). The world is flat: A brief history of the twenty-first century. New York: Farrar, Straus and Giroux.

Hruska-Riechmann, S., \& Grasha, A. F. (1982). The Grasha-Riechmann student learning style scales. In J. Keefe (Ed.), Student learning styles and brain behavior. Reston, VA: National Association of Secondary School Principals.

Lopes, F. \& Morais, P. (2002). Lessons learnt from the teaching of IS development. Journal of Information Technology Education, 1(2), 103-112. Retrieved from http://jite.org/documents/Vol1/v1n2p103112.pdf

Myers, M. (2003). An IS capstone project: The Mywick property management system, Journal of Information Systems Education, 14(3), 235-239.

Neville, K. \& Adam, F. (2003). Integrating theory and practice in education with business games. Informing Science Journal, 6, 61-73. Retrieved from http://inform.nu/Articles/Vol6/v6p061-073.pdf

Noll, C.L. \& Wilkins, M. (2002). Critical skills of IS professionals: A model for curriculum development, Journal of Information Technology Education, 1(3), 143-154. Retrieved from http://jite.org/documents/Vol1/v1n3p143-154.pdf

Tuttle, S.M. (2001). A capstone course for a computer information systems major, Proceedings of the Second Annual CCSC on Computing in Small Colleges Northwestern Conference, 42-49.

\section{Biography}

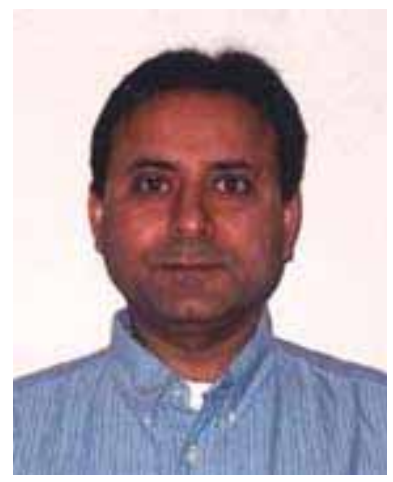

Dr. Anil Kumar is an Associate Professor in the Business Information Systems Department at Central Michigan University. He has published more than 40 articles on global IT management, technology-mediated learning and IS education. His current research focuses on globalization \& technology, and technology-mediated learning. Prior to his academic appointment, he spent several years working in the IS industry. He is active in several professional organizations and serves on the editorial board of the Journal of Global Information Technology Management and the International Board of Reviewers of the Journal of Information Technology Education. 